Brit. J. industr. Med., 1963, 20, 110.

\title{
THERMAL COMFORT IN THE HOT HUMID TROPICS OF AUSTRALIA
}

\author{
BY \\ C. H. WYNDHAM \\ From the Applied Physiology Laboratory of Transvaal and Orange Free State Chamber of Mines, Johannesburg, \\ and the Department of Physiology, Medical School, University of Witwatersrand, Johannesburg
}

(RECEIVED FOR PUBLICATION JUNE 19, 1962)

Day and night comfort votes were recorded from Caucasian residents at Weipa, a mission station in the hot humid tropics of North Queensland, Australia. The limit of day comfort for more than $50 \%$ of the men was $81 \cdot 5^{\circ} \mathrm{F}$. $\left(27 \cdot 5^{\circ} \mathrm{C}\right.$.) "normal" corrected effective temperature; the night limit was $78 \cdot 0^{\circ} \mathrm{F}$. $\left(25 \cdot 5^{\circ} \mathrm{C}\right.$. $)$. Day comfort limits correlated well with air conditions at which sweat was apparent: night limits correlated with the amount of bed covering. Evidence of a change over 14 days in day comfort limit was found. Limitations in the effective temperature scale for expressing the "oppressive nature" of night air conditions are pointed out. Criticism is voiced of the use of dry bulb temperature instead of the effective temperature scale in conditions of high wet bulb temperatures with high relative humidity, such as in the hot humid tropics.

The hot humid regions of the tropics of Australia are reputed to contain much mineral wealth. The successful exploitation of these natural resources will depend upon "white" Australians being able to live and work in these areas. One of the possible difficulties in the way of establishing permanent communities is discomfort due to heat and humidity. Whether discomfort will prove to be a major determinant in this question depends upon the frequency with which certain "comfort" limits of ambient air conditions are exceeded during the summer months. Information on the upper limits of hot humid air conditions for comfort is sparse for Caucasians accustomed to living in the tropics. Almost no information exists on the rate at which "expatriates" from temperate zones adjust to a new level of thermal comfort, as distinct from acquiring the physiological manifestations of acclimatization.

The opportunity of conducting a comfort survey was taken therefore during a three months' sojourn* from February to May 1960, at Weipa on the Gulf of Carpenteria coast of Cape York Peninsula, Queensland, Australia. The subjects were 16 white Australians who were stationed at a bauxite exploratory camp about half a mile from the mission station

*The writer's primary object was a study of the heat reactions of Australian aborigines, undertaken while holding a Royal Society Nuffield Foundation Commonwealth Fellowship.

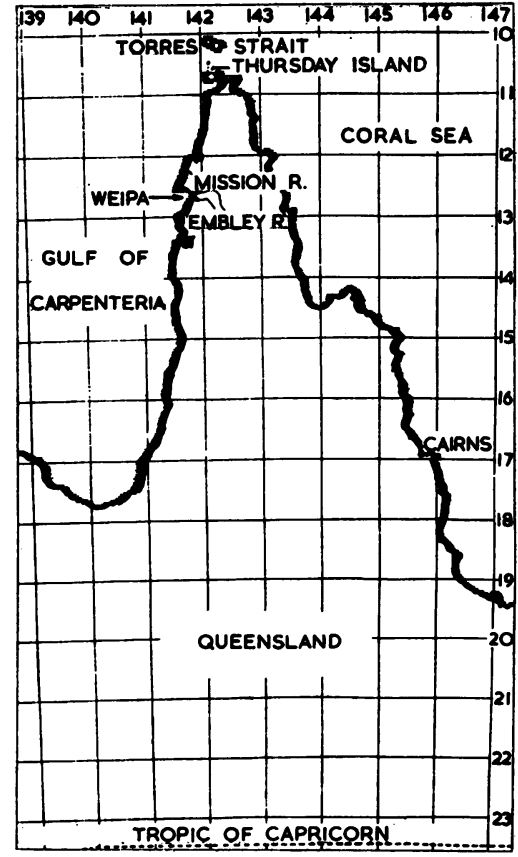

Weipa Mission is shown on this map of North Queensland. It is situated on S. latitude $12^{\circ} 40^{\prime}$ on the coast of the Gulf of Carpenteria. 
at Weipa (see map). Most of the men had been at the station for some years apart from their annual vacation over Christmas time.

The survey was designed to include both day and night comfort. Lack of information on the upper limit of ambient air conditions for comfort at night is a surprising gap in our knowledge of thermal comfort. As far as I am aware, no definitive study, based upon adequate numbers chosen at random, has been made to determine the limits of air conditions at night that are uncomfortable and cause a loss of sleep. The subject is mentioned but receives cursory treatment in reports on tropical living (Macpherson, 1956). Night discomfort could, however, prove to be one of the decisive factors in the successful establishment of a community at Weipa. As an illustration of this contention, consider two tropical areas, one hot and humid and the other hot and dry. They may have the same effective temperatures during the stressful part of the day, i.e. from 11:00 to 17:00 hours. In hot dry climates temperatures characteristically fall during the night to a level that may be cool or even mildly cold. In hot humid regions, night temperatures remain high and cause discomfort or even a loss of sleep. The combined effect of discomfort during the day and disturbance of sleep at night, especially if cumulative, is calculated to have a great effect on morale, working efficiency, and even mental and physical health.

\section{Methods}

In the study on day comfort, each man was handed a questionnaire at lunch-time (see appendix, p. 117). He was asked to place a mark against the appropriate answer. The questions related to his subjective feeling in relation to the air conditions in the room on a seven-point scale of warmth. He was also asked to note the presence or absence of sweat and, if present, to describe the situation. Several questions were included, which, it was considered, would influence the rating given to the air condition on the seven-point scale. The community was entirely male with little in the way of social hierarchy, and there were no inhibitions about dress. In these circumstances there was a good likelihood of the men adjusting the amount of clothing naturally to the feeling of comfort or cold or warmth produced by the air conditions. Hence a question was included on the amount of clothing being worn at the time the questions were answered. Secondly, common experience indicates that the sensation of comfort in particular air conditions is related to some extent, although the relation is not known in a quantitative way, to the level of activity in the hour before the survey and also to whether the man worked in direct sunlight or not. This information was requested.

The night questionnaire was divided into two parts (see appendix, p. 117). One dealt with the hours before midnight and the other with the hours after midnight. The same questions were asked as in the day survey about the individual's subjective sensations towards the air conditions. In addition he was asked to state whether sleep was disturbed and, if so, whether or not the disturbance was due to heat. Another question dealt with the amount of covering used during the night, i.e. whether the individual slept naked, wore pyjamas only, pyjamas plus a sheet, or pyjamas plus sheet and blanket. The original plan was that the first part of the questionnaire, dealing with the man's sensation of comfort at the time of retiring, should be answered by the subject before going off to sleep, and the other in the morning just after he rose from his bed. In practice, this plan, desirable as it was, was abandoned and the questions were put at breakfast-time. This is to be regretted, but so many difficulties arose from the original plan that the men's co-operation was in jeopardy. An unfortunate omission from the questionnaire was any reference to sweating at night. Sweating leading to moist sheets can undoubtedly contribute to discomfort and it would be useful to know what association there is between discomfort at night and disturbance of sleep.

Air conditions during the periods in which men cast their votes were measured by the observer. Dry bulb, wet bulb, and globe thermometer temperatures were recorded in the lunch-room over the period of the meal. The first two measurements were repeated at 8 p.m., 10 p.m., 12 p.m. , and at 7 a.m. the following morning. An assessment of the air movement was made on the Beaufort scale after a series of unsuccessful attempts had been made to measure wind velocity with a vane anemometer. The lack of success was due to the gusty nature of the air movement. These air conditions are converted to effective temperature values on the basic nomogram which applies to men stripped to the waist, sitting at rest.

\section{Results}

Day Comfort.-Each man's "comfort" vote is plotted against the mean effective temperature value for the lunch period on the 20 days of the study in Fig. 1. The following conclusions can be drawn from these data: (a) Up to effective temperatures of $80^{\circ} \mathrm{F}$. $\left(26 \cdot 6^{\circ} \mathrm{C}\right.$.) more than $50 \%$ of the men were comfortable and no man was too hot; $(b)$ above effective temperatures of $80^{\circ} \mathrm{F}$. $\left(26 \cdot 6^{\circ} \mathrm{C}\right.$.) few men were comfortable and those who were were all sedentary employees; (c) above effective temperatures of $82^{\circ} \mathrm{F}$. $\left(27 \cdot 8^{\circ} \mathrm{C}\right.$.) some men, especially the cooks, felt too hot; and $(d)$ below effective temperatures of $78^{\circ} \mathrm{F}$. $\left(25.5^{\circ} \mathrm{C}\right.$.) it was mainly men engaged on moderate-to-hard rates of work in the hour before lunch who voted that the air conditions were warm.

In Fig. 2 are plotted the results on the presence or absence of sweating and the amount of clothing worn at various effective temperature values. The relevant points are that (a) above effective temperatures of $80^{\circ} \mathrm{F}$. $\left(26 \cdot 6^{\circ} \mathrm{C}\right.$.) most men sweated and those who did not were all engaged on sedentary work. In general, those who sweated all over the 


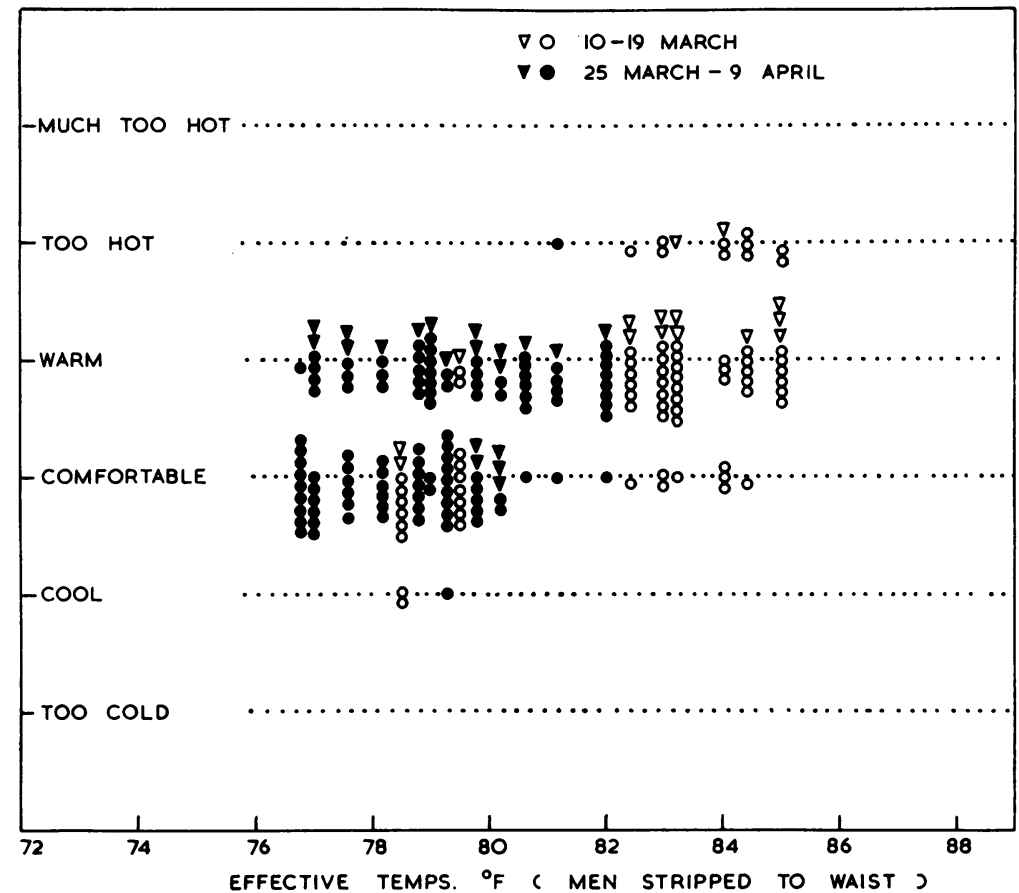

Fig. 1.-Day comfort votes plotted against basic effective temperature of men living in hot humid climate of Weipa. Men engaged on moderateto-hard work $\nabla$; on light work anywhere 0 .

IG. 2.-Location of sweating and amount of clothing plotted against basic effective temperature. $\nabla$ and $\mathrm{O}$ have same designation as in Fig. 1 .

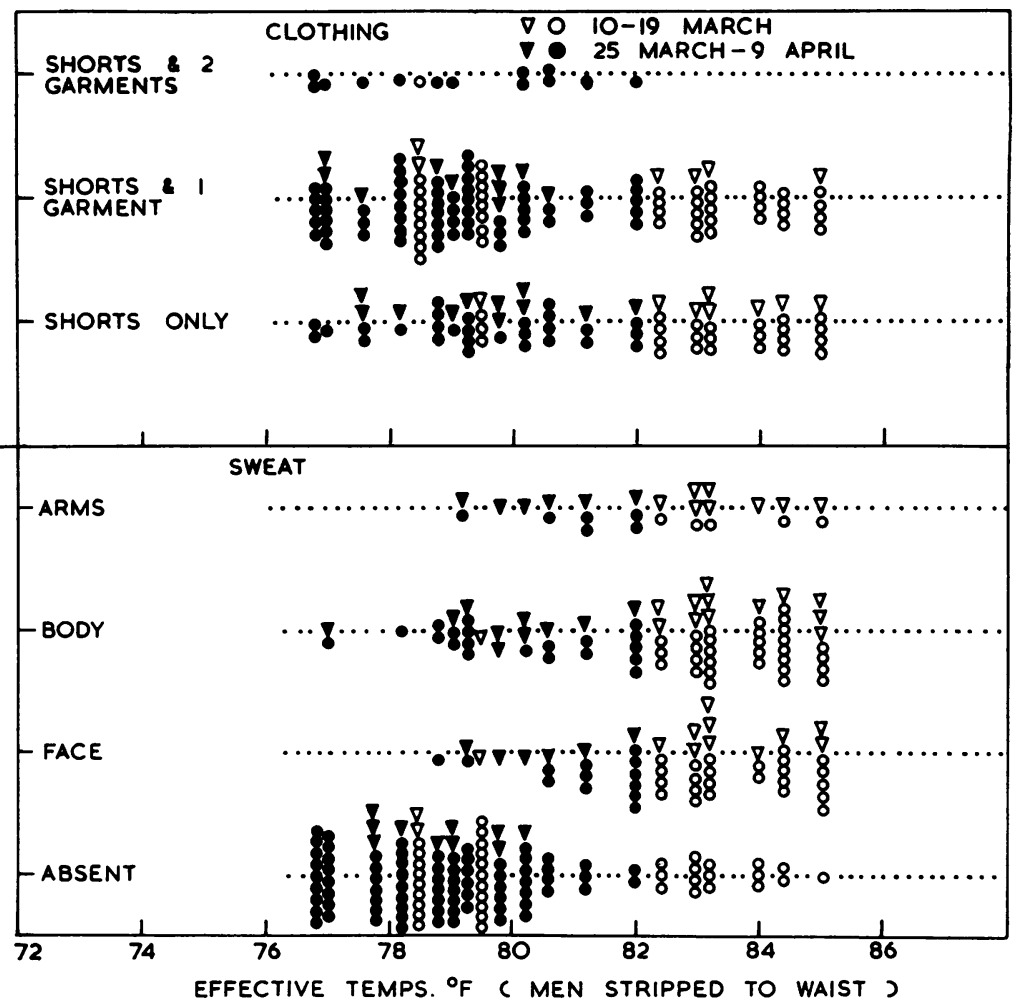


body, especially on the arms, were the cooks and men engaged on moderate-to-hard work tasks before the lunch break; $(b)$ below effective temperatures of $80^{\circ} \mathrm{F}$. $\left(26 \cdot 6^{\circ} \mathrm{C}\right.$.) few men sweated and those who did were mainly the cooks and men working at moderateto-hard rates before lunch; and $(c)$ there is no clear demarcation in the effective temperature value at which the men decrease the amount of clothing worn, as happens with comfort and sweating. There is, however, an obvious trend towards a reduction in the amount of clothing worn during the lunch break as the effective temperature rises.

In Fig. 3 is plotted the distribution of men working in the open and under galvanized iron roofs and also the distribution in relation to rates of work. These results are for the hour before lunch. The figure shows that the distribution of men between work in the open and under galvanized iron roofs is relatively constant. The fact that no man said he worked hard in air conditions with effective temperature values above $83^{\circ} \mathrm{F}$. $\left(28.3^{\circ} \mathrm{C}\right.$.) may be quite fortuitous and should be investigated further.

A further point needs to be made on these results. The period March 10 to 19 was characterized by a succession of days with effective temperatures of $83^{\circ} \mathrm{F} .\left(28 \cdot 3^{\circ} \mathrm{C}\right.$.) and above at lunch-time, but on one day there was a sharp drop, due to cloud, to an effective temperature value of $78 \cdot 5^{\circ} \mathrm{F}$. $\left(25 \cdot 8^{\circ} \mathrm{C}\right.$.). Most men called this air condition comfortable, three called it cool, and not one felt it was warm; only the cook sweated, and not a single man had lunch without a shirt. These results contrast markedly with the reactions of the same men after March 25 when a cooler period had set in. About $25 \%$ of the men then said they were warm at effective temperatures even lower than $78 \cdot 5^{\circ} \mathrm{F}$. $\left(25 \cdot 8^{\circ} \mathrm{C}\right.$.); a few said they sweated, and these were mainly the kitchen staff; and a number stripped off their shirts during lunch.

Night Comfort.-Night comfort votes are given in Fig. 4 as well as the effective temperature values at which men claimed that their sleep was disturbed by heat. From this figure it can be concluded that (a) up to effective temperatures of $76 \cdot 5^{\circ} \mathrm{F} .\left(24 \cdot 7^{\circ} \mathrm{C}\right.$.) most men felt comfortable; $(b)$ as the effective temperature fell from $76^{\circ} \mathrm{F}$. $\left(24 \cdot 4^{\circ} \mathrm{C}\right.$.) to $71^{\circ} \mathrm{F}$. $\left(21.6^{\circ} \mathrm{C}\right.$.) an increasing number of men felt cool; (c) above effective temperatures of $76 \cdot 5^{\circ} \mathrm{F}$. $\left(24 \cdot 7^{\circ} \mathrm{C}\right.$.) few men felt comfortable. The majority felt warm,

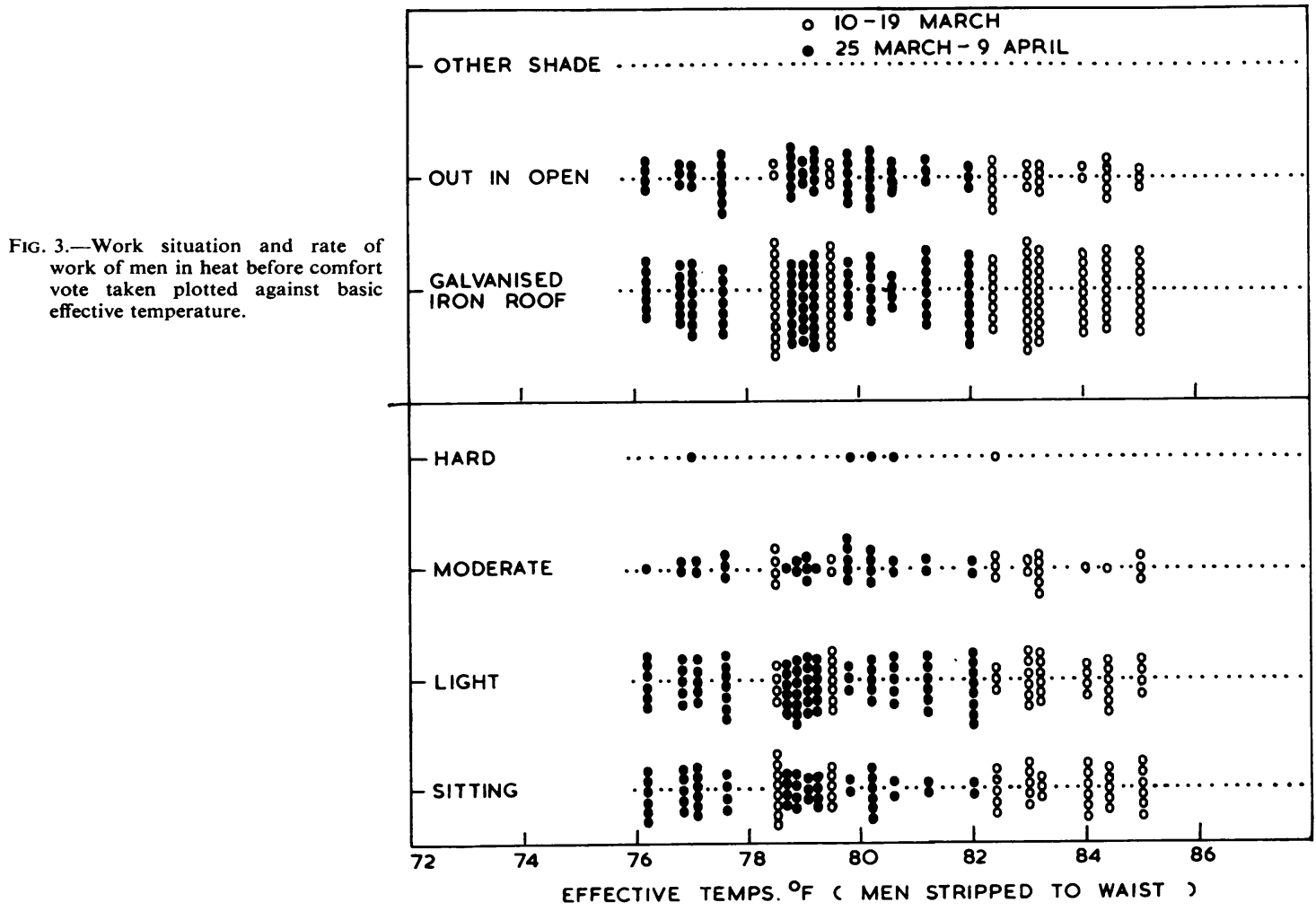


but up to effective temperatures of $78 \cdot 2^{\circ} \mathrm{F} .\left(25 \cdot 6^{\circ} \mathrm{C}\right.$.), the highest during this period, no one stated that he was too hot; and $(d)$ the sleep of a few men was disturbed by heat when the effective temperature rose above $77^{\circ} \mathrm{F} .\left(25^{\circ} \mathrm{C}\right.$.).

The interaction between the effective temperature of the air conditions and the amount of night coverings is given in Fig. 5. This demonstrates that (a) in effective temperatures above $76 \cdot 5^{\circ} \mathrm{F} .\left(24 \cdot 7^{\circ} \mathrm{C}\right.$.) most men slept in pyjamas only, some slept naked, and only a few used a sheet as well; and $(b)$ as the effective temperature fell from $76 \cdot 5^{\circ} \mathrm{F}$. $\left(24 \cdot 7^{\circ} \mathrm{C}\right.$. $)$ to

Fig. 4.-Night comfort votes, plotted against basic effective temperature.
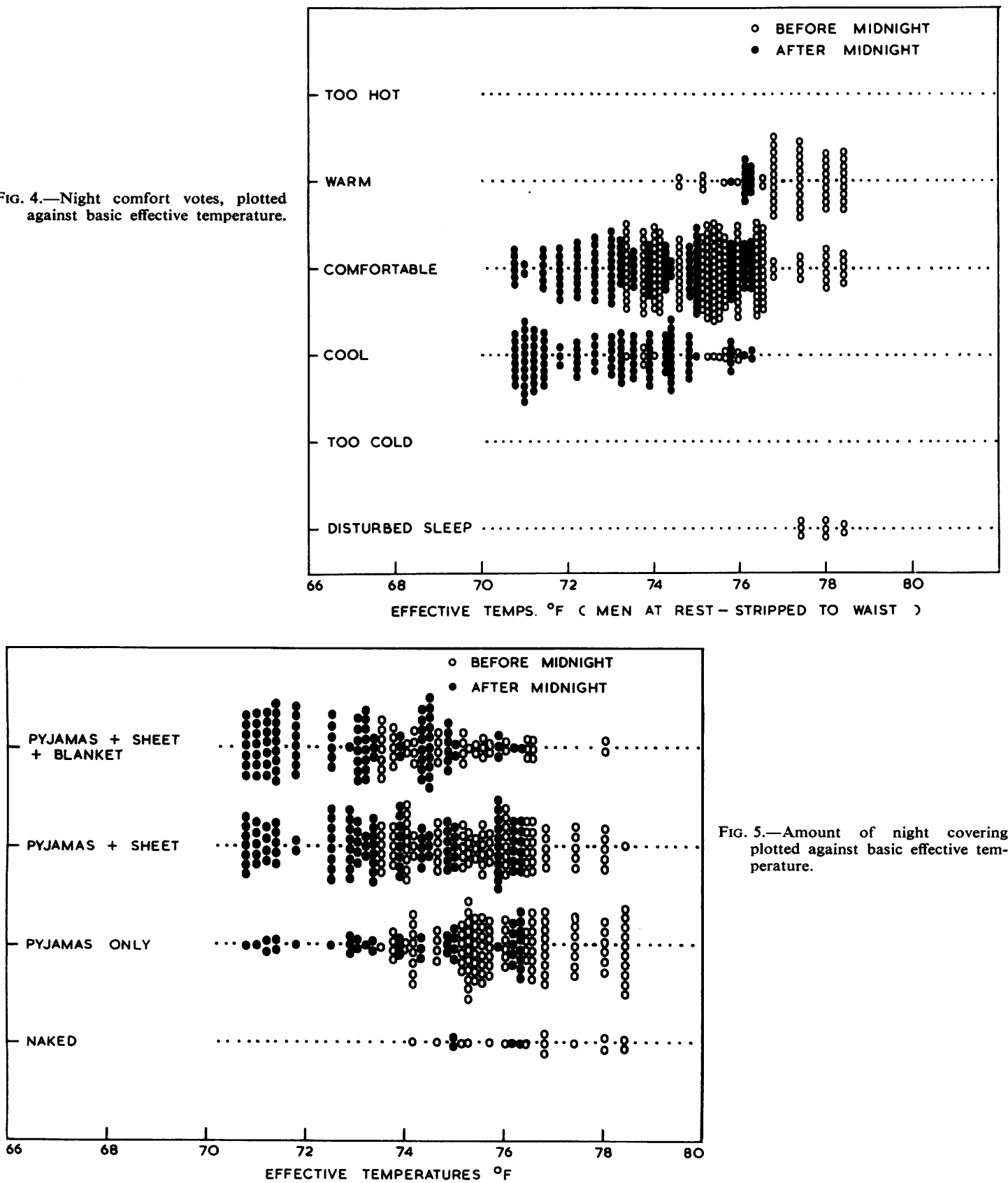

Fig. 5.-Amount of night covering plotted against basic effective temperature. 
$71^{\circ} \mathrm{F}$. $\left(21 \cdot 6^{\circ} \mathrm{C}\right.$.) fewer men slept in pyjamas only and an increasing number drew up a blanket during the night. No men slept naked in effective temperatures below $74^{\circ} \mathrm{F}$. $\left(23 \cdot 3^{\circ} \mathrm{C}\right.$.).

\section{Discussion}

Day Comfort.-On the basic scale $80^{\circ} \mathrm{F} .\left(26.6^{\circ} \mathrm{C}\right.$. $)$ is the effective temperature at which there is a sharp transition between air conditions which more than $50 \%$ of the subjects record as comfortable and those which the majority find warm. (This limit on the nomogram for men dressed in light summer suits is $81.5^{\circ} \mathrm{F}$. $\left(27 \cdot 5^{\circ} \mathrm{C}\right.$.) effective temperature on the "normal" scale.) In putting forward this limit, it must be emphasized that the subjects taking part in the study were able to make a spontaneous and "natural" adjustment in the amount of clothing worn during the lunch-break. There were no restrictions placed upon men stripping to the waist if they so wished. In hot humid climates these adjustments are highly desirable for both physiological and psychological reasons. They do, however, flaunt one of the deeply ingrained conventions, probably impressed upon men by female dictates and considerations of social prestige in the hierarchy. The limit could well be shifted down by about $2^{\circ} \mathrm{F}$. $\left(1^{\circ} \mathrm{C}\right.$.) effective temperature were the situation to arise in which the minimum "respectable" clothing for men was a suit, a shirt, and a tie. There is another limitation to the general applicability of these data to conventional communities. The study was conducted on men. It is not certain that these limits would apply to women and children. It is, of course, highly desirable that communities in the tropics should comprise family units.

This limit of $81.5^{\circ} \mathrm{F}$. $\left(27 \cdot 5^{\circ} \mathrm{C}\right.$.) normal effective temperature is considerably higher than those reported in Britain and the United States of America but is comparable with the limits given in other studies in the tropics. These are summarized in the Table.

TABLE

UPPER LIMIT FOR COMFORT OF LIGHTLY CLAD PERSONS IN SUMMER

\begin{tabular}{l|c|l}
\hline \multicolumn{1}{c|}{ Region } & Effective Temperature & \multicolumn{1}{|c}{ Reference } \\
\hline Britain & $68^{\circ} \mathrm{F} .\left(20^{\circ} \mathrm{C}\right.$.) & Bedford (1948a) \\
U.S.A. & $7^{\circ} \mathrm{F} .\left(24 \cdot 5^{\circ} \mathrm{C}.\right)$ & Bedford (1948b) \\
Iran & $77^{\circ} \mathrm{F} .\left(25^{\circ} \mathrm{C}.\right)$ & Grocott (1948) \\
Calcutta & $7^{\circ} 7^{\circ} \mathrm{F} .\left(25^{\circ} \mathrm{C}.\right)$ & Rao (1952) \\
Singapore & $7^{\circ} \mathrm{F} .\left(25.5^{\circ} \mathrm{C}.\right)$ & Ellis (1953) \\
Malaya & $\mathbf{8 1}^{\circ} \mathrm{F} .\left(27^{\circ} \mathrm{C}.\right)$ & Webb (1952) \\
\hline
\end{tabular}

The most cogent point that emerges from an examination of the Table is the rise in the upper limit of comfort as one moves from the temperate to the tropical regions. This is especially true of the limits in the hot humid tropical areas. Furthermore, winter limits are much lower than summer ones. Thus the upper limit in winter in Britain is $63^{\circ} \mathrm{F}$. $\left(17 \cdot 2^{\circ} \mathrm{C}\right.$.) compared with $68^{\circ} \mathrm{F}$. $\left(20^{\circ} \mathrm{C}\right.$.) effective temperature in summer. Comparable figures for the United States of America are $71^{\circ} \mathrm{F} .\left(21.6^{\circ} \mathrm{C}\right.$.) and $76^{\circ} \mathrm{F}$. $\left(25 \cdot 4^{\circ} \mathrm{C}\right.$.). It is reasonable to infer from these data that a man judges an air condition as comfortable, cold, or warm in relation to the general level of effective temperature he has been experiencing for some time past. It is not known in any quantitative and scientific way how long it takes invididuals coming from a temperate climate to the tropics to make an adjustment in the upper limit of comfort when they are continuously exposed to new and hotter air conditions. The major physiological adjustments in acclimatization occur within a week (Eichna, Ashe, Bean, and Shelley, 1945). It cannot be inferred, however, that alterations in thermal sensations necessarily follow the same time scale as physiological reactions. Some light is thrown on this problem by the present results. There was a striking change in the men's assessment of the thermal comfort of two air conditions with similar effective temperatures over a period of two weeks. In the first instance they had adapted to relatively severe heat, i.e. effective temperatures in the $80^{\prime} \mathrm{s}^{\circ} \mathrm{F}$. $\left(27-32^{\circ} \mathrm{C}\right.$.), and in the second to a cooler succession of air conditions. In the first period $78 \cdot 5^{\circ} \mathrm{F} .\left(25 \cdot 8^{\circ} \mathrm{C}\right.$.) felt comfortable and even cool to two men, and all wore shirts. In the second period the same effective temperature felt warm to $50 \%$ of the men, and some removed their shirts. This result illustrates the highly flexible nature of man's temperature-sensing mechanisms to changes in air conditions. A useful analogy would be to regard man's capacity to adapt the sensation of comfort to the general level of effective temperature he has been experiencing as similar to the variable "set-point" in thermostatic control equipment. It is not known what part is played by psychology or physiology in these alterations in the "set-point" of comfort. Sensory adaptation is a well-known phenomenon in physiology. The adaptation of temperature sensation could be regarded as similar in its mechanism. The time period of two weeks over which the alteration in comfort sensation occurred in this study was fortuitous. There is clearly room for considerable research into the length of time it takes for these adaptations to occur. In an age of fast jet travel between temperate and tropical regions such studies would be of more than academic interest. In the same context, no really definitive studies have been made of inter- and intra-individual differences in temperature sensation to air conditions in comfortable and warm limits. 
The short time over which this alteration in temperature sensation was observed raises certain difficulties. It follows logically that the upper limits of comfort can be defined only in relation to the general effective temperatures over a period, as yet undefined, before the study. It may be that the upper limits follow a well-defined trend in relation to seasonal alterations in the air conditions. If this proves to be the case, it would not be possible to establish a single comfort zone for a particular geographical region; it would be necessary to state the extremes for winter and summer. There is supportive evidence for this suggestion in the differences between winter and summer upper limits of comfort reported above for Britain and the United States of America. The other problem relates to quantifying the degree of discomfort populations can be expected to experience in hot dry, and in hot humid climates. I have proposed elsewhere (Wyndham, 1961) that two such climates can be compared by the frequency with which the air conditions of the two areas exceed a level of effective temperature, accepted as the upper limit of comfort. In the hot dry condition, heat during the day continues relentlessly day after day. In the hot humid tropics, the worst heat occurs when the rains stop for a week or so and the dry bulb temperature rises, with a concomitant rise in the wet bulb. Such extreme conditions are generally relieved by heavy tropical rains when the gap between wet and dry bulb temperatures disappears. In the first situation, the desert condition, there is never any relief from heat during the day. In the second situation, the fall in effective temperature during heavy rains is experienced as a great relief because the air conditions are cool relative to the heat of the preceding week. A mere enumeration of the number of days exceeding certain comfort limits does not take account of this difference between hot dry and hot humid climates.

Night Comfort.-At $76 \cdot 5^{\circ} \mathrm{F}$. $\left(24 \cdot 7^{\circ} \mathrm{C}\right.$.) effective temperature there was a sharp transition from air conditions in which the majority of men felt comfortable to those in which the majority felt warm. Substance is lent to the fact that this effective temperature is a critical one for night comfort by the observation that above $76 \cdot 5^{\circ} \mathrm{F}$. $\left(24 \cdot 7^{\circ} \mathrm{C}\right.$.) most men slept in pyjamas only, whereas below this effective temperature additional bed covering was used. Few subjects had their sleep disturbed by heat, and none felt too hot even at $78^{\circ} \mathrm{F}$. $\left(25 \cdot 5^{\circ} \mathrm{C}\right.$.) effective temperature. Further studies would be desirable during the even warmer nights of January and February to establish the limit of air conditions which are too hot, in which sleep is disturbed, and in which sweating occurs. This information is essential in estimating the frequency in the hot humid tropics with which night discomfort, possibly leading to sleeplesness, is likely to occur in populations living in these climates. Night discomfort and disturbed sleep, especially if cumulative and associated with discomfort due to heat during the day, might render a hot humid tropical area uninhabitable. Serious consideration would need to be given to installing air-conditioning in the bedrooms to provide conditions for restful sleep. In this regard it is appropriate to mention the fact that in a survey of the air conditions at Darwin, Cairns, and Weipa in the hot humid tropics of Australia (Wyndham, 1961), the percentage of nights in the worst months of the year with no air movement was very high. At Weipa the provision of good ceiling fans to provide at will an air movement of $150 \mathrm{ft} . / \mathrm{mm}$. ( $45.7 \mathrm{~m} . / \mathrm{min}$.) would cut down the number of nights in the uncomfortable range from over 100 to less than 40 in the year.

Discomfort at night occurred at $76 \cdot 5^{\circ} \mathrm{F} .\left(24 \cdot 7^{\circ} \mathrm{C}\right.$.) compared with $80^{\circ} \mathrm{F}$. $\left(26 \cdot 6^{\circ} \mathrm{C}\right.$.) effective temperature during the day. In the evening the men were generally engaged in sedentary occupations and slept during the night. The day results show that a low rate of metabolism would tend to raise the upper limit of comfort and not lower it, as is the case here. Variations in the amount of clothing can also be excluded as an explanation for these differences. Below an effective temperature of $77^{\circ} \mathrm{F}$. $\left(25^{\circ} \mathrm{C}\right.$.) during the day most men wore a shirt in addition to shorts, and this was also the usual form of dress in the evenings. However, at bed-time, when the effective temperature rose above $76 \cdot 5^{\circ} \mathrm{F} .\left(24 \cdot 7^{\circ} \mathrm{C}\right.$.), men slept in pyjamas only and a few were naked. At night, when men lie on a mattress, about $50 \%$ of the body surface is rendered ineffective for heat loss by convection and radiation. Conventional mattresses act as a layer of insulation and are warm and uncomfortable in the hot humid tropics. Consideration should be given to designing a mattress for the tropics which has a low heat capacity and can be ventilated.

A striking difference between day and night conditions with the same effective temperature is that when the effective temperature at night exceeded $77^{\circ} \mathrm{F}$. $\left(25^{\circ} \mathrm{C}\right.$.) the air conditions were described as "oppressive". This term was never used for the same effective temperature during the day. One possible explanation for this difference in characterizing two climates with the same effective temperature is that at night the air was still. Possibly the effective temperature scale does not give sufficient weight to the adverse effect on comfort of still air in this temperature range and of air nearly saturated with water vapour.

In this same regard it is noted that there is a 
tendency for certain authors to discard the effective temperature scale in favour of the dry bulb temperature as a comfort index of the air conditions (Koch, Jennings, and Humphreys, 1960; Macpherson, 1961). This procedure may be valid for low dry bulb temperatures in the range $60^{\circ}$ to $70^{\circ} \mathrm{F}$. $\left(15 \cdot 5^{\circ}\right.$ to $21^{\circ} \mathrm{C}$. $)$ and the humidities of England in which Bedford (1948 a \& b) found that comfort votes correlated almost as well with dry bulb temperature as with effective temperature. To extrapolate this procedure to conditions in which the air temperature rises above $75^{\circ} \mathrm{F}$. $\left(23.9^{\circ} \mathrm{C}\right.$.), and especially into the $80^{\prime}{ }^{\circ} \mathrm{F}$. $\left(>26.5^{\circ} \mathrm{C}\right.$. $)$, is unjustified. To take an extreme case, $85^{\circ} \mathrm{F} .\left(29 \cdot 5^{\circ} \mathrm{C}\right.$. $)$ dry bulb temperature is relatively comfortable if the wet bulb temperature is low, as in the desert; the same air temperature in the hot humid tropics with the air nearly saturated with water vapour is very uncomfortable. This example is not open to question. The same is true for temperatures of $80^{\circ} \mathrm{F}$. $\left(26 \cdot 6^{\circ} \mathrm{C}\right.$.) and even down to $75^{\circ} \mathrm{F}$. $\left(23.9^{\circ} \mathrm{C}\right.$.). Somewhere below $75^{\circ} \mathrm{F}$. $\left(23.9^{\circ} \mathrm{C}\right.$. $)$ the influence of wet bulb temperature on comfort decreases, but no one has produced any definitive information on this point. To discard the effective temperature scale in favour of the dry bulb temperature as a comfort index in the hot humid tropics in air conditions in which the dry bulb temperatures frequently exceed $80^{\circ} \mathrm{F}$. $\left(26 \cdot 6^{\circ} \mathrm{C}\right.$.) during the day is a highly dubious procedure.

I wish to record my sincere appreciation of the help and encouragement afforded by Mr. S. Christie, Technical Director of Comalco, and Dr. W. George, Chief Medical Officer, in conducting the studies that led to this paper.

\section{REFERENCES}

Bedford, T. (1948a). Basic Principles of Ventilation and Heating, p. 96 Lewis, London. (1948b). Ibid., p. 99.

Eichna, L. W., Ashe, W. F., Bean, W. B., and Shelley, W. B. (1945) J. industr. Hyg., 27, 59.

Ellis, F. P. (1953). J. Hyg. (Lond.), 51, 386.

Grocott, J. F. L. (1948). J. Instn Heat. Vent. Engrs, 16, 36.

Koch, W., Jennings, B. H., and Humphreys, C. M. (1960). Trans. Amer. Soc. Heating, Refrigerating and Air-conditioning Engrs, 66, 264.

Macpherson, R. K. (1956). In Environmental Problems in Tropical Australia. Report to Govt. Australia, Canberra.

(1961). Report on Studies in the Preferred Thermal Environment. Rao, M. N. (1952). Indian J. med. Res., 40, 45.

Webb, C. G. (1952). J. Instn Heat. Vent. Engrs, 20, 189.

Wyndham, C. H. (1961). In Problems of Tropical Living at Weipa. Report to Technical Director of Comalco, Melbourne.

\title{
APPENDIX
}

Day Comfort Vote

1. Name

Date

2. Please put a cross against the term which best describes your sensation in relation to the present temperature conditions:

Much too hot ............

Too hot

.............

Cool

Too cold

Much too cold

3. Please put a tick against the conditions applicable in the following:

(a) Sweat: Absent............ Present on face........... on body.....

(b) Physical activity in last hour: Sedentary.......

Hard work............

(c) Where were you working in last hour? Out in the open............ Under a galvanized iron roof. In the shade of trees............ Other...........

(d) What air movement do you feel now? None.......... Slight.......... Moderate........... Strong.....

(e) What clothes are you wearing? Shorts only........... Shorts and shirt........... Shorts, vest, and shirt............. Shorts, shirt, and tie........... Shorts, shirt, and coat. Long socks. Short socks.

Night Comfort Vote

Date

1. Name.

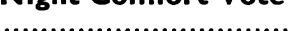

2. Please put an " $x$ " (for before midnight) and a " $\sqrt{ }$ " (for after midnight) for the term which best describes your sensation in relation to last night's temperature conditions:

Much too hot

Too hot Too cold

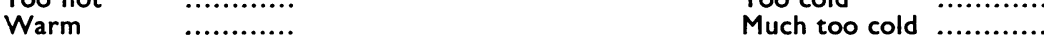

.............

3. Please put an " $x$ " (for before midnight) and a " $\sqrt{ }$ " (for after midnight) against the conditions applicable last night:

(a) Sleep: Undisturbed.......... Disturbed by heat.......... by insects........... by noise............. by worry............

(b) Bed clothes: Pyjama coat and shorts.

Pyjama shorts.

Naked

Sheet

\begin{abstract}
Blanket............
\end{abstract}
(c) Air movement: None..................

Moderate

Strong

4. Did you have a fan going?

4 